\title{
The Employment-Crime Association for Individuals Convicted of a Sexual Offense in their Youth
}

\author{
Chantal van den $\operatorname{Berg}^{1}$ (D) . Geert Mesters $^{2}$
}

Received: 15 October 2016 / Revised: 10 July 2017 / Accepted: 14 July 2017 /

Published online: 3 August 2017

(C) The Author(s) 2017. This article is an open access publication

\begin{abstract}
Objective We study the bi-directional relationship between employment and crime for individuals convicted for a sexual offense in their youth (JSO) and investigate the moderating influences of age and employment duration.

Method A bi-variate dynamic binary choice model is developed to allow for interactions between employment and crime. The model takes into account statistical aspects such as state dependence and unobserved heterogeneity.

Results For a sample of $N=493$ JSO, who are observed in early adulthood, age 18 until 28, we find significant negative predictive effects for employment on property offending and vice versa. For other types of offenses, the model indicates that the negative correlation with employment is due to spurious effects. This holds for all ages, but the negative effect of employment on property offending becomes stronger for the older cohorts, while the effect of property offending on employment decreases in magnitude. Employment duration is found to be a mild moderating factor.

Conclusion The evidence in favor of bidirectional negative relationships among offending and employment that increase in magnitude with age suggests the importance of theories that emphasize cumulative (dis)advantage, such as social control theory.
\end{abstract}

Chantal van den Berg

c.j.w.vanden.berg@vu.nl

Geert Mesters

geert.mesters@upf.edu

1 Department of Law and Criminology, VU University Amsterdam, Initiumgebouw, De Boelelaan 1077, 1081 HV Amsterdam, The Netherlands

2 Department of Economics and Business, Universitat Pompeu Fabra, Ramon Trias Fargas 25-27, 08005 Barcelona, Spain 
Keywords Life-course $\cdot$ Reciprocal $\cdot$ Employment-crime association · Juvenile sexual offending $\cdot$ Employment quality

\section{Introduction}

Employment is considered one of the most important means for promoting desistance from criminal activities and enabling reintegration of ex-offenders into society; see [10]. Theories from different fields emphasize different mechanisms for the negative association between employment and offending. The majority of criminological, sociological, and economic theories hypothesize a reducing effect of employment on criminal activity $[7,16,22,39,57,60]$. This theoretical assumption is supported by a large body of empirical evidence that is summarized in recent reviews by Mustard [45] and Lageson and Uggen [31].

In the opposite direction, crime and the reactions to offending imposed by society and the criminal justice system are often argued to reduce employment probabilities as a result of stigmatization or the process of job skill erosion $[18,33,51$, $52,84]$. This latter finding is less robust, as more mixed empirical evidence exists. This is especially true for the effects of incarceration on employment, see the recent discussions in Kling [28], Apel and Sweeten [5], and Loeffler [35].

Finally, factors such as age and employment quality moderate the relationship between employment and crime. For age, intensive employment is found to increase delinquency during adolescence and is associated with a reduction in offending after the transition into adulthood [53, 64, 73, 74]. The influence of employment quality, rather than the mere status of employment, was established by a number of empirical studies $[15,57,59,72,74,78,80,81]$. Different definitions of employment quality are used and we consider employment duration in our study below.

The complex association between employment and crime is typically investigated and documented for high-risk offenders as well as general offender populations. For juveniles with sexual offending histories, the relationship between employment and crime has received less attention.

This is understandable from a practical perspective as reliable samples and data are hard to obtain for this subgroup. However, there are several specific reasons for why understanding the employment-crime association in early adulthood for individuals convicted for a sexual offense in their youth (we will further refer to these individuals as juvenile sex offenders) is important.

First, such juveniles have been found to be at risk for persistent criminal behavior (general criminality) because of problematic background characteristics, such as adverse childhood experiences, psychosocial deficits in childhood and adolescence, adverse environmental circumstances, and antisocial attitudes and beliefs [62]. These characteristics can cause prolonged criminal activity over the life-course and limit employment chances [43].

Second, in many countries, finding stable employment has become difficult if an individual has been convicted for a sexual offense. For example, in The Netherlands, 
the country where this study took place, all individuals convicted for a sexual offense (juveniles as well as adults) are excluded for life from several types of employment in which they might be able to spend unsupervised time with children or individuals dependent on their care. A broad range of occupations are included within this rule: for instance, taxi or bus drivers, caregiver jobs, babysitters, and janitors at schools.

Hence, given the problematic background characteristics of juvenile sex offenders and their increasing exclusion from the legal labor market, it is important to study the interaction between employment and crime. A negative interaction would imply that employment can potentially be an effective policy for reducing crime.

Recent studies have found that the heterogeneity in the criminal careers of juvenile sex offenders is similar to that of juvenile offenders who have not committed a sex offense [11, 12, 36, 37, 75]. Also, Tewksbury [70] and Van den Berg et al. [76, 77] have shown that employment is correlated with reduced criminal behavior in juvenile sex offenders. To the best of our knowledge, no evidence exists for the reciprocal effect of crime on employment for the juvenile sex offender, nor for the moderating influences of age and employment duration.

In light of the findings discussed above, the current study makes three contributions. First, we study the individual-level relationship between employment and crime for a large sample of $(N=493)$ juvenile sex offenders who are observed in early adulthood between ages 18 and 28. This subgroup of offenders received limited attention within the empirical literature, specifically with regard to life-course development and the protective effect of employment. Second, the reciprocal effect of crime on employment for the juvenile sex offenders is studied. For general offender populations, the effect of crime on employment has been extensively studied using a variety of methods, whilst for juvenile sex offenders the evidence is missing. Third, we investigate the moderating influences of age and employment duration. This contribution can be viewed as a robustness check for our main contributions, but as the moderating influences of age and employment duration have been firmly established for general offender populations it seems reasonable to assume that similar age-graded and duration-graded perspectives for the employment-crime association are likely for juvenile sex offenders.

In order to disentangle the interactions between employment and crime, we propose a reduced form panel data model that is closely related to the dynamic binary choice models that are used in the labor economics literature [25-27]. In particular, we develop a bi-variate dynamic binary choice model that simultaneously models the employment and crime outcomes on the individual level. We control for unobserved heterogeneity and allow for state dependence in both the employment and crime outcomes, see also Alessie et al. [1] and Mesters et al. [42] as well as Thornberry and Christenson [71] for an earlier contribution along these lines. In order to study the moderating influences of age and employment duration, the baseline model is extended to allow for age-varying parameters. Also, we vary the definition of the employment outcome. We discuss the proposed panel data models in detail and compare their performance to standard panel data models. 
The remainder of this paper is organized as follows. The next three sections discuss general criminological and sociological theories that explain the relationship between employment and crime. Next, we explain how the employment-crime relationship for juvenile sex offenders can be understood within these general theories. This forms the basis for our empirical study where we study the bi-directional relationship between employment and crime (any sex offenders and investigate the moderating influences of age and employment duration. The final section presents our general discussion and conclusions.

\section{How Employment Affects Crime}

The link between employment and crime is documented by different theoretical mechanisms. Some of these general theories use an economic point of view to explain the relationship between offending and employment. The underlying framework is the concept of the "homo economicus," or economic man, that views humans as rational beings who weigh the costs and benefits of their behavior out of self-interest and the desire for economic gain [82].

Rational choice theories build on this concept by assuming that individuals make decisions whether to employ legal (paid employment) or illegal means (like stealing, robbing, etc.) to obtain the desired outcome [7, 16]. Strain theory by Merton [40] also focuses strongly on utilitarian crimes committed to achieve economic success in society (measured by wealth and material possessions) that cannot be achieved through legitimate means. These theories explain the association between employment and offending by financial aspects that result from time allocation, implying that sufficient wages are the main feature of employment influencing the reducing effect on income-generating crimes.

The use of a framework focused on non-economic gains allows for a broader understanding of the relationship between employment and offending [82]. For instance, the routine activities approach states that there is an instantaneous effect of employment on offending, as routine activities change daily time structuring. When an individual is engaged in regular employment, time to engage in criminal opportunities is limited [14]. In a related fashion, when an individual spends more time at their job, the values, attitudes, and behavior of others in the same positions are learned. These values and attitudes associated with the job culture will mostly disapprove of criminal activity [69]. In addition, the supervision of co-workers may have an inhibiting effect on offending [22].

The empirical findings for the association between employment and offending are somewhat mixed. A large proportion of the studies is cross-sectional and can therefore not examine within individual differences [74]. However, longitudinal studies that use careful control methods in an attempt to deduce causality have found a reducing effect of employment on criminal activity for various samples $[15,42,57,59,61$, $73,78,82]$. Some studies found no link between offending and employment $[24,38]$. 


\section{How Crime Affects Employment}

Several theories also suggest that offending affects employment outcomes. Hirschi [22] states that prior offending can weaken social bonds which may prevent individuals from future employment. Sampson and Laub [58] also suggest the weakening of conventional bonds to society by the gradual process of cumulative disadvantage and state dependence. Sampson and Laub [57] identify cumulative disadvantage as the dynamic process of childhood antisocial behavior and adolescent delinquency as a possible cause of adult crime that limits individuals from obtaining adult social bonds. The process of state dependence postulates that delinquent behavior has a causal effect on future delinquent behavior by reducing social capital attributed by conventional social bonds, due to incarceration as well as exclusion form society after incarceration [57]. Moreover, if an individual is incarcerated it is impossible to obtain specific work experience, this will limit chances of employment after incarceration since job skills are often insufficient [23]. Thus, individuals who have spent a considerable amount of time incarcerated become unattractive employees.

It is not merely the lack of job skills that cause ex-offenders to be unattractive employees, the label received after being incarcerated also adds to the unattractiveness [8]. Criminal behavior, and interaction with the criminal justice system, labels an individual as an offender, tainting the individuals' self-image and public identity which in turn affects future life outcomes [47]. If an individual has been incarcerated the public will associate the ex-offender with negative characteristics, such as untrustworthiness or aggressiveness [23]. An employer can be influenced by these assumed negative characteristics not to hire an ex-offender. Additionally, the self-image of the ex-offender can also be influenced by labeling. This process, the self-fulfilling prophecy [8], causes the ex-offender to conform to the image others have of him or her, the image of a criminal. If an individual develops a criminal self-image he or she might not expect to be hired by employers, and thus will lose faith in finding a job. This fear of rejection causes lower self-esteem and hopelessness associated with demoralization that produces the very behavior for which a person is then rejected [34]. Moreover, Becker [8] underlines that the label of offender will reduce associations with non-delinquent peers, conventional institutions and roles, thus limiting employment chances. In sum, some theories state that the official responses to offending, such as conviction and incarceration, will lead to stigma and the association of the ex-offender with negative characteristics, while others argue that the deterioration of human capital explains the negative influence on employment.

For the effect of offending on employment a large body of literature has documented difficulties of obtaining legal employment after criminal behavior, particularly after detention [5, 35, 50-52, 56]. The majority of studies focus on the consequences of incarceration rather than convictions and a variety of methods are used. Pager [50] and Pager et al. [52] use field experiments and find that the mark of a criminal record significantly decreases the probability of getting a job. Apel and Sweeten [5] and Loeffler [35] use registered data and advanced statistical methods, 
to show that a substantial part of the established negative relationship between incarceration and employment might be spurious. Other factors predating the incarceration, like schooling, detachment from legal work, and social associations may also influence the employment chances after incarceration.

\section{Moderating Effects of Age and Employment Duration}

Several moderating factors may influence the interaction among employment and offending. Two important of such factors are age and employment duration [59, 60]. We discuss several theories that incorporate these variables as moderating factors.

\section{Age}

Most theories concerning the employment-offending association can be positioned in an age-graded framework, indicating the moderating effect of age, where different outcomes for the employment-offending relationship are assumed for different agegroups. In such a framework, certain aspects of employment that have a reducing effect on offending for adults may have an increasing effect, or no effect, for adolescents. Adolescents are usually employed in minimum wage jobs with little prospects due to limited schooling, therefore the likelihood of the presence of delinquent coworkers increases [86]. Full-time employment may thus increase criminal activity for adolescents, as they are inclined to learn adult values and attitudes from their older co-workers according to learning theory [69]. These behaviors can be positive when the co-workers exhibit conventional behavior. However, less conventional co-workers may introduce the adolescents to deviant behavior, increasing the chances of delinquent behavior [86]. Also, social control becomes limited as adolescents spend more time away from parents and school when employed. Moreover, due to increased monetary abilities, adolescents are able to spend unstructured time with peers in pubs, clubs, and other settings associated with deviance. Adults, however, will be more inclined to use the economic gains of employment to support their family instead of spending it on unstructured time with peers.

Sampson and Laub [57] also postulate such an age-graded effect as they use a life-course perspective that focuses on the changes in relevant institutions of social control that vary by age. For instance, social bonds with family, school, and peers are important for the adolescence period. When the value that these social bonds hold for an individual exceeds the costs of offending (e.g., losing friends), delinquency will become less attractive. Sampson and Laub [57] named this value social capital; the importance that the ties to society hold for the individual. After adolescence, a period of preparation for adulthood follows. This so-called emerging adulthood ranges from about age 18 up to 25 and is characterized by exploration with limited parental control, and with the aim of establishing a unique personal identity [6]. In this period, a shift occurs in relevant institutions of social control, from family, school, and peers to more prominent bonds with partners and co-workers. For employment, Arnett [6] argues that in the early stages of emerging adulthood the individuals will experience job instability (e.g., short and temporary employment) while they are still exploring 
their options. Yet, in the later stages of emerging adulthood employment explorations become more serious and enduring, since stakes will be higher as stable employment is needed as a foundation for adult life [6]. Overall, several theories state that the nature of employment changes with the coming of age and its effect on delinquency may thus vary per age period or even year.

With regard to the effect of offending on employment, little is known about the influence of age. Sampson and Laub [57] argue that cumulative disadvantage enhances over time with childhood antisocial behavior and adolescent delinquency causing adult crime due to the weakening of social bonds. Therefore, one might argue that chances of employment will decrease more strongly over time if an individual continues offending. The labeling of an adolescent might also cause difficulties in obtaining employment and education. This might result in a self-fulfilling prophecy, where the self-image of an offender might become more negative over time, decreasing employment chances. This process might be experienced somewhat more by juvenile offenders, as juveniles are still developing a self-image and thus more susceptible to the label of "criminal" [6]. Alternatively, one may argue that with age frequent offenders simply select into jobs where limited skills are required and stigmatization is less important. This would imply that offending has a lesser, or zero, effect on the employment probability.

Some studies found the effect of employment on offending to depend on age. For instance, age. For instance, [73] analyzed data from an experimental employment project and found that in the age group of 27 and over, recidivism rates were significantly lower when employed than when not employed. For teenagers, Wright and Cullen [86] found evidence suggesting that during employment spells, offending may actually increase. Using the National Longitudinal Survey of Youth (NLSY), several studies looked into the effect of (intensive) employment [2-4, 53, 87]. Paternoster et al. [53] found mixed results for the relationship between intensive employment and criminal behavior in adolescents, dependent on the statistical method used. The first analysis showed a significantly reinforcing relationship between intensive employment and crime for adolescents. However, in a second analysis that controlled for selection effects using fixed and random effects models they found no significant effects. Apel et al. [2] also found no effect and Apel et al. [3] found limited evidence for a reducing effect of employment on offending in adulthood. Therefore, these authors conclude that the association of employment and offending differs for adults and adolescents. Staff and Uggen [67] emphasize this, as they find that certain aspects of employment which are deemed important for adults (status, wages, etc.) seem to increase delinquency in adolescence. Furthermore, Skardhamar and Savolainen [65] highlight the moderating effect of age as they pose that employment is a consequence of natural desistance which occurs with maturation over time, rather than a cause of desistance.

\section{Employment Duration}

Implicitly, the theory by Arnett [6] also hypothesizes a moderating effect of employment duration when interacted with age. With maturation the importance of stable employment becomes more clear and as stated by Arnett [6] is needed as a foundation 
for adult life. Moreover, Sampson and Laub [57] and Sampson and Laub [60] view the accumulation of human and social capital as a gradual and cumulative process. Therefore, over time social capital obtained by stable employment will increase due to the accumulating bond to conventional society. This bond will enhance the possibilities for the individual to knife-off the (delinquent) past, engage in routine activities, invest in new relationships that foster social support causing direct or indirect supervision and control, and to allow identity change [60, p. 34]. For this reason, Sampson and Laub [60] used employment stability as a measure of employment quality in their initial empirical work. The findings supported their theory as their measure of employment quality was found to be important in predicting desistance [57]. In their later work Sampson and Laub [57] collected life history narratives from 52 men in the Glueck's sample. The findings again supported the assumption that stable employment is a salient life-event that may lead to desistance. Crutchfield and Pitchford [15] also found that the time spent being employed (duration) significantly reduced offending. However, some studies using stability or duration as a measure of employment found no effect on offending $[19,54]$. The study by Nagin and Waldfogel [49] even found that conviction decreases job stability in juvenile offenders. Van der Geest et al. [78] found a similar result, as the juvenile delinquents in their sample had relatively more temporary jobs.

\section{Sexual Offending by Juveniles and Employment}

The theoretical mechanisms by which employment may reduce offending and vice versa do not exclude individuals convicted for a sexual offense. However, specific theories for the interaction between crime and employment for individuals convicted for a sexual offense do not exist. Therefore, it is difficult to formulate specific hypothesis regarding the employment-crime association for juvenile sex offenders beyond those that can be derived from the general theories. We emphasize that our interest is in general offending behavior and not specifically sexual offending as the majority of the juvenile sex offenders have criminal careers that resemble the careers of general high-risk offenders and sexual offending typically only occurs very infrequently [21, $36,37,75]$.

In light of this, the same economic, rational choice, and routine activity theories may be applicable for juveniles with sexual offending histories when explaining why employment reduces offending. Similarly, the process of job skill erosion and stigmatization can explain a negative effect of offending on employment. However, this reciprocal effect is possibly larger for juvenile sex offenders, because the label or stigma that is attached to sexual offending is often larger when compared to other types of offenses [17]. This implies that finding a job may be harder for juvenile sex offenders, which can lead to further job skill erosion. Evidence for increased stigmatization is found in the legal employment and housing restrictions that are often imposed on those convicted for a sexual offense.

The legal employment restrictions that are imposed on juvenile sex offenders have a potentially large impact on the employment-offending relationship. In The 
Netherlands, the country where this study took place there are no public registries or housing restrictions for individuals convicted for a sexual offense. However, since 2004, all individuals convicted of a sexual offense are excluded for life from specific types of employment in which they might be able to spend unsupervised time with children or individuals dependent on their care. A broad range of occupations are included under this rule, for instance taxi or bus drivers, caregiver jobs, babysitters, and janitors at schools. For the above reason, the employment opportunities for individuals with a sexual offending history in The Netherlands are limited. Therefore, they might experience more difficulties in obtaining stable employment than other (ex-) offenders.

In addition, juveniles with sexual offending histories have been found to differ from general offenders in terms of increased psychological and psychiatric disorders [66] and lower social competence [83]. These characteristics could also influence employment chances as it makes them less appealing to employers. Empirically, only a few studies investigated the extent to which employment reduces offending in juvenile sex offenders. The studies that were conducted emphasized the importance of stable employment; we are not aware of any studies that have focused on the age-graded effect of the employment-crime association in samples of juvenile sex offenders. Kruttschnitt et al. [30] found sex offender treatment and stable employment to be the only aspects related to reduced general recidivism rates in a sample of adult males convicted for a sexual offense. Another study by Hanson and Harris [20] found that the sex offenders with the highest re-offending risk were those who lacked stable employment. Within clinical practice the importance of employment is also acknowledged as a rehabilitative factor. For example, the Good Lives Model of offender rehabilitation assumes that individuals convicted for a sexual offense, share the common life goals and objectives of all human beings, like excellence in employment, that can enhance psychological well-being and reduce offending [32].

We are aware of only one study that explicitly looked into the relationship between employment and offending for juvenile sex offenders. Van den Berg et al. [77] studied a large sample of juvenile sex offenders over a long period from adolescence to young adulthood (age 18 up to 28). They found that the sample members start off on the labor market early, but with the coming of age the employment rate stagnates and even declines after age 27. In comparison with low educated Dutch males, the sample members even started off their employment career with a somewhat higher percentage of employment participation. After the age of 26, the sample members were found to be lagging behind in comparison to the employment participation of the average Dutch male and the low educated Dutch males. They explain this phenomenon by the fractured employment careers with many short contracts and different job types (regular employment and employment through an employment agency), but also the lack of schooling and unappealing personal characteristics (lacking social skills, low IQ, psychological problems). However, despite that the sample faces many (legal) barriers in the obtaining of stable and qualitative employment, and the found low quality and instability of the employment, employment still significantly reduced general offending. This finding raises many questions about the mechanisms behind the relationship of employment and offending. The current study 
aims to uncover some of the possible mechanisms that could explain the established relationship of employment and offending later in life among youth convicted of a sexual offense.

\section{The Current Study}

The current study builds upon previous work on the employment-crime association for juvenile sex offenders $[76,77]$. We focus on the bi-directional relationship between employment and crime and the influence of the moderating factors age and employment duration on this relationship. We explore the employment-crime association in two steps.

First, the theoretical and empirical evidence indicates that the relationship between employment and crime is bi-directional. In order to disentangle, the bidirectional relationship we propose a bi-variate dynamic binary choice model. A more detailed discussion of the general model is given below. There we also provide a detailed comparison to more common uni-variate dynamic binary choice models. We highlight the advantages of the bi-variate model.

Second, we investigate how both directions of the employment-crime association are moderated by age and employment duration. We extend the bi-variate dynamic binary choice model in novel ways to investigate the moderating influences of age and employment length. In particular, we adopt different definitions for the employment outcome which depend on the length of the employment spell and we allow the parameters that measure the interactions among employment and crime to fluctuate with age.

After we have documented our empirical findings we return to our theoretical framework and establish which theories support the employment-crime association for juvenile sex offenders. We also discuss to what extend our findings differ from those that are found for other high-risk offenders.

\section{Methodology}

\section{Sample}

The research group of 493 juvenile sex offenders was established using a sex offense as the selection offense, committed between 1988 and 2001. Their age at the selection offense ranged from 10 to 17 years, with an average of 14.4 years (SD 1.8). The selection offense consisted of at least one conviction for a contact sexual offense (where physical contact between offender and victim occurred) ranging from sexual assault to rape. During the sampling offense all perpetrators had an active role. About $16 \%$ of the sample committed the offense with at least one co-offender, the remaining $84 \%$ were solo offenders. In 2009 and 2010, information was collected from register records about offending, employment and personal life circumstances (marriage and parenthood) and is complete since age 18 . The mean follow-up time by then was 14 years, and the sample members were between age 18 and 40 with an average of 28.7 
years (SD 3.9). Before the end of the observation period, seven persons died and fourteen emigrated (according to the Dutch Municipal Personal Records Database).

Previous research found a high prevalence for psychological and psychiatric disorders in those convicted for a sexual offense $[62,79]$. Moreover, juvenile sex offenders were found to be socially isolated, as their social skills were less developed causing difficulties in their social functioning within society [62, 79]. For the current sample, we found similar adverse background characteristics. About half of the sample members have been diagnosed with a psychiatric or psychological disorder. Eighty percent had limited social interactions with peers and $81 \%$ had low self-esteem. Moreover, the sample is characterized as, on average, highly neurotic and introvert. All in all, the current sample of juvenile sex offenders strike as vulnerable, in terms of problematic background characteristics, such as adolescent and childhood deviant behavior, adverse personality and environmental characteristics and low educational levels. These characteristics lead to prolonged criminal activity over the life course and limit employment chances [43]. Furthermore, Van den Berg et al. [75] showed that not only the psychological profiles of the juvenile sex offenders are comparable to high-risk juveniles in other studies $[78,80]$, but that also the heterogeneity in their criminal careers is similar to that of other high-risk juvenile offenders.

\section{Procedures and Measures}

Three sources of register data were used: judicial documentation, municipal marriage and parenthood registrations, and centralized employment records.

All information on employment was obtained from the database "SUWINET" of the Ministry of Social Affairs and Employment in the Netherlands and from the trade register of the Netherlands Chamber of Commerce (Kamer van Koophandel). The first data source holds individual level information on employment by an employer, by an employment agency and social benefits. In order to use the employment data in our analysis, the number of days employed was calculated from the start to end date of an employment contract. The second data source refers to business ownership information, and registration and termination date of the business were used to compose the employment variable. Combining the two data sources, we constructed a variable that counts the number of days per year an employment contract(s) spanned. We included employment when a sample member had regular employment with an employer, was a business owner, was employed through sheltered workshops for the (mentally) disabled, or employed through a temporary employment agency. Permission for the use of this data was granted by the Ministry of Social Affairs and Employment.

The offending data originates from the Judicial Documentation (JD) registered at the Judicial Documentation Center in Almelo. The JD can be considered as a "rap sheet" and contains all offenses registered for prosecution in the Netherlands, regardless of the verdict. The offenses in the JD are registered by date of perpetration, offense committed (coded according to the Dutch Criminal Code, Wetboek van Strafrecht), conviction date and sentence. For this study, we excluded all offenses for which the sample member was acquitted or when prosecution dropped the case on "technical grounds" (mainly when the case was expected to end in acquittal). 
For our dependent variable crime, we consider three categories for defining the outcome: property, violent, and a broader category of any type of offending. The property offending category includes embezzlement, theft, forgery, and counterfeiting, breaking and entering, burglary, fraud, and dealing in stolen property. The violent offending category includes assaults, threats, homicides, and sexual offenses. The any type of offending variable contains: sexual offending, (non-sexual) violent offending, property offending, and other serious offending (consisting mainly of drug offenses and offenses as described in the Dutch law on weapons and ammunition). The offending data is complete for all sample members from age 12 up to the end of the data collection. However, for the analysis we used age 18 to 28 , since we are interested in the effect of employment on offending and our employment data is complete from age 18 and onward. The Dutch Ministry of Security and Justice granted permission for the use of this data.

Additionally, several control variables were used, all measured at the individual level. These control variables are exposure (percentage of time out of prison per year), marriage and children. These variables are all dynamic variables and may lead to changes in offending (Sampson and Laub [57]; e.g. for marriage and divorce: Bersani et al. [9]; Stolzenberg and D' Alessio [68]). Exposure will influence offending since in our sample not all individuals have served time in prison: for the sample members who were in prison their time-at-risk or exposure time to re-offend will be shorter than for the never incarcerated sample members [46]. By including marriage and children, we control for their influence on the relationship between offending and employment.

\section{Analytic Strategy}

The analytic strategy is build around a bi-variate dynamic binary choice model that facilitates the simultaneous modeling of the employment and offending outcomes. The baseline model specification is closely related to the specification considered by Alessie et al. [1] and Mesters et al. [42] who build on the earlier work of Thornberry and Christenson [71]. We start by explaining the model.

Let $y_{1, i, t}$ and $y_{2, i, t}$ denote the binary employment and offending outcomes for individual $i$ at age $t$. For the employment outcome, we use the threshold of 90 days to select an individual into the employment category. This is in accordance with other studies that have used 90 days employment a year as a cut-off point in order to establish if the employment was "serious" [77, 78, 80]. For the offending outcomes, we set $y_{2, i, t}=1$ if an offense was committed and $y_{2, i, t}=0$ if no offense was committed. We vary the definition of an offense according to the categories defined above.

The model for the employment outcome is given by

$$
\begin{aligned}
& y_{1, i, t}=\left\{\begin{array}{l}
1 \text { if } y_{1, i, t}^{*}>0 \\
0 \text { if } y_{1, i, t}^{*} \leq 0
\end{array},\right. \\
& y_{1, i, t}^{*}=y_{1, i, t-1} \gamma_{11}+y_{2, i, t-1} \gamma_{12}+x_{i, t} \beta_{1}+\xi_{1, t}+\mu_{1, i}+\epsilon_{1, i, t},
\end{aligned}
$$

where outcome $y_{1, i, t}=1$ indicates that individual $i$ was employed for more than 90 days at age $t$. Corresponding one-to-one with $y_{1, i, t}^{*}>0$, which transforms the binary 
outcomes for $y_{1, i, t}$ into continuous outcomes of the latent process $y_{1, i, t}^{*}$. This process is interpretable as the transformed probability for employment, which is determined by six different components: $y_{1, i, t-1} \gamma_{11}$ measures the effect of the previous employment outcome on the current employment probability, $y_{2, i, t-1} \gamma_{12}$ captures the effect of the previous crime outcome, $x_{i, t} \beta_{1}$ captures the effects of the observed control variables, $\mu_{1, i}$ is the individual-specific effect, $\xi_{1, t}$ is the age dummy and $\epsilon_{1, i, t}$ the disturbance term.

A similar structure is utilized for the binary crime outcome denoted by $y_{2, i, t}$, which is related to the latent process $y_{2, i, t}^{*}$. We have

$$
\begin{aligned}
& y_{2, i, t}=\left\{\begin{array}{l}
1 \text { if } y_{2, i, t}^{*}>0 \\
0 \text { if } y_{2, i, t}^{*} \leq 0
\end{array},\right. \\
& y_{2, i, t}^{*}=y_{1, i, t-1} \gamma_{21}+y_{2, i, t-1} \gamma_{22}+x_{i, t} \beta_{2}+\xi_{2, t}+\mu_{2, i}+\epsilon_{2, i, t},
\end{aligned}
$$

where the latent process $y_{2, i, t}^{*}$ is determined by the lagged outcomes of employment $y_{1, i, t-1} \gamma_{21}$ and crime $y_{2, i, t-1} \gamma_{22}$, the observed control variables $x_{i, t} \beta_{2}$, the individualspecific effect $\mu_{2, i}$, the age dummy $\xi_{2, t}$, and the disturbance term $\epsilon_{2, i, t}$.

The vector of observed control variables $x_{i, t}$ includes controls for marriage, children and exposure (percentage of time spent out of prison per year). All these control variables can potentially influence employment and crime. To control for unobserved heterogeneity, we include random individual-specific effects $\left(\mu_{i, j}\right)$ and fixed age dummies $\left(\xi_{j, t}\right)$. The age dummies are common for all individuals.

We assume that the individual-specific effects $\mu_{j, i}$ are random which has the advantage that the correlation between the individual-specific effects of the employment and crime equations can be modeled. The interpretation of this coefficient is discussed below. A disadvantage of this random assumption versus an alternative fixed effects assumption is that there can be correlation between the random effects $\mu_{j, i}$, the control variables $x_{t}$, and the initial conditions $y_{j, 0}$. If this correlation is not accounted for several problems will occur, see Mundlak [44] and Chamberlain [13] for a discussion regarding linear models and Wooldridge [85] for nonlinear models. To circumvent these issues, we follow Wooldridge [85] and model the random effects $\mu_{j, i}$ as functions of the control variables and the initial observations. ${ }^{1}$ Finally, the disturbances in Eqs. 1 and 2 are modeled by a bi-variate normal distribution with

${ }^{1}$ Specifically, we consider

$$
\begin{aligned}
& \mu_{1, i}=\delta_{10}+\sum_{s=1}^{T} x_{i, s} \delta_{1 s}+y_{1, i, 0} \lambda_{11}+y_{2, i, 0} \lambda_{12}+v_{1, i}, \\
& \mu_{2, i}=\delta_{20}+\sum_{s=1}^{T} x_{i, s} \delta_{2 s}+y_{1, i, 0} \lambda_{21}+y_{2, i, 0} \lambda_{22}+v_{2, i},
\end{aligned}
$$

where

$$
\left[\begin{array}{l}
v_{1, i} \\
v_{2, i}
\end{array}\right] \sim N\left(\left[\begin{array}{l}
0 \\
0
\end{array}\right],\left[\begin{array}{cc}
\sigma_{v, 1}^{2} & \rho_{v} \\
\rho_{v} & \sigma_{v, 1}^{2}
\end{array}\right]\right),
$$

Given that the parameters $\delta$ and $\lambda$ capture the correlations between the random effects and the initial observations and control variables, the remaining individual-specific effects $v_{1, i}$ and $v_{2, i}$ follow a bivariate normal distribution which has mean zero and correlation parameter $\rho_{v}$. 
correlation parameter $\rho_{\epsilon} \cdot{ }^{2}$ Alternatively, we could assume that the disturbances follow an extreme value type 1 distribution to obtain a logit model for the outcomes. The benefit of the normal assumption is that the contemporaneous correlation can be captured between the outcomes through the correlation parameter $\rho_{\epsilon}$.

The baseline model is summarized by Eqs. 1 and 2. All parameters of the model can be summarized in the vector $\psi$. The estimation of the model parameters is performed by the Monte Carlo maximum likelihood methods that are developed in [41].

\section{Discussion and Relationship to Uni-variate Models}

Now that the baseline model has been described it is useful to discuss its interpretation. The main parameters of interest are $\gamma_{11}, \gamma_{12}, \gamma_{21}$ and $\gamma_{22}$. The parameters $\gamma_{11}$ and $\gamma_{22}$ capture the state dependence ${ }^{3}$ in the employment and crime outcomes. In other words, they capture the predictive effect of being employed or criminally active at age $t-1$ on the corresponding transformed probabilities for employment and crime at age $t$. The parameters $\gamma_{12}$ and $\gamma_{21}$ capture the predictive cross-effects from crime on employment and from employment on crime.

First, regardless of the control variables, we emphasize that we are not estimating the effect of employment at age $t$ on being criminally active at age $t$. The estimates for the parameters $\gamma$ pertain to predictive effects of employment and crime at age $t-1$ on these outcomes at age $t$. Getting consistent estimates of crime on employment at the same ages requires instrumental variables. Valid instruments are not available for the current study and in general they are typically not available for individual-level longitudinal studies. Nevertheless, the predictive estimates remain very relevant from a policy perspective. For instance, if being employed predicts a lower crime rate for the next age period this would still yield important implications for policy.

To explain how the model controls for unobserved heterogeneity, we first consider only the model for the employment outcome itself:

$$
y_{1, i, t}=\left\{\begin{array}{l}
1 \text { if } y_{1, i, t}^{*}>0 \\
0 \text { if } y_{1, i, t}^{*} \leq 0
\end{array}, \quad y_{1, i, t}^{*}=y_{1, i, t-1} \gamma_{11}+x_{i, t} \beta_{1}+\xi_{1, t}+\mu_{1, i}+\epsilon_{1, i, t},\right.
$$

Here, the influence of crime has been removed completely and the model reduces to a uni-variate dynamic binary choice model. The model can distinguish between unobserved heterogeneity $\left(\mu_{1, i}\right)$ and state dependence $y_{1, i, t-1} \gamma_{11}$, see Hyslop [25]. Both phenomena (unobserved heterogeneity and state dependence) can explain why employment in period $t$ can predict employment in period $t+1$. The distinction

\footnotetext{
${ }^{2}$ In particular, we have

$$
\left[\begin{array}{c}
\epsilon_{1, i, t} \\
\epsilon_{2, i, t}
\end{array}\right] \sim N\left(\left[\begin{array}{l}
0 \\
0
\end{array}\right],\left[\begin{array}{cc}
1 & \rho_{\epsilon} \\
\rho_{\epsilon} & 1
\end{array}\right]\right)
$$

which corresponds to the familiar bi-variate probit model for the outcomes $y_{1, i, t}$ and $y_{2, i, t}$.

${ }^{3}$ state dependence is the process of previous criminal delinquent behavior increasing the chances of future criminal behavior due to incarceration and exclusion from society, which reduces the social capital attributed by conventional social bonds [57]. The same can be assumed for employment, as previous employment will increase chances of future employment, simultaneously increasing social capital.
} 
between the influence of unobserved heterogeneity, which creates spurious persistence, and the state dependence is important. The former would suggest that individuals remain employed because of underlying characteristics, such as abilities and preferences, that select them into employment whereas the latter suggests that structural features of being employed have a direct effect on being employed in the next period. Think for example about the social bonds and financial security that employment creates which could be a direct motivation to remain employed.

A similar uni-variate model can be formulated for the crime outcomes.

$$
y_{2, i, t}=\left\{\begin{array}{l}
1 \text { if } y_{2, i, t}^{*}>0 \\
0 \text { if } y_{2, i, t}^{*} \leq 0
\end{array}, \quad y_{2, i, t}^{*}=y_{2, i, t-1} \gamma_{22}+x_{i, t} \beta_{2}+\xi_{2, t}+\mu_{2, i}+\epsilon_{2, i, t},\right.
$$

In this model, the influence of employment has been removed. Similarly, this univariate model can explain persistence in the crime outcomes by either unobserved heterogeneity and state dependence. These different explanations for persistence in crime outcomes have extensively been discussed from a theoretical perspective in [48]. It is important to note that only if the control variables adequately capture the unobserved heterogeneity the estimate for the state dependence parameter $\gamma_{22}$ is consistent.

In addition to the uni-variate models, the bi-variate model can account for crosseffects between employment and crime. Following a similar reasoning as above, if crime in period $t$ predicts employment in period $t+1$ this can be due to spurious correlation (as captured by $\rho_{v}$ and $\rho_{\epsilon}$ ) or due to the cross effect from crime on employment (parameter $\gamma_{12}$ ). The same holds for the predictive effect of employment on crime. Hence, if the estimates for $\rho_{v}$ and $\rho_{\epsilon}$ are equal to zero we could estimate both equations separately.

When the parameters $\rho_{v}$ and $\rho_{\epsilon}$ are a priori set to zero while in reality they are not zero, then the spurious correlation is typically attributed to the cross-effects. Generally, under the assumption that the true spurious correlation $\rho_{v}$ is negative, the cross dependence parameters would be overestimated. In particular, we would assign the spurious correlation between employment and crime to the structural parameters $\gamma_{12}$ and $\gamma_{21}$.

This distinction between unobserved heterogeneity and cross-effects is important for understanding the dynamic relationship between employment and crime. For example if the parameter $\gamma_{21}$, which captures the lagged effect of employment on crime is not significant but $\rho_{v}$ is significant and negative, than this would imply that individuals who select into employment with a higher probability and at the same time select into crime with a lower probability. In this scenario, there would be no advantage of increasing employment opportunities for $\mathbf{J}$ since the negative correlation is entirely spurious. In our empirical study, we show the results from bi-variate and uni-variate models to demonstrate these different implications.

\section{Extensions for Moderating Age and Employment Length}

The basic dynamic binary choice model is extended in several ways to investigate the moderating influences of age and employment length. First, to investigate the 
moderating effects of age on the structural part of the relationship between employment and crime we model the parameters $\gamma$ as age-varying processes. In other words, we change $\gamma_{11}, \gamma_{12}, \gamma_{21}$ and $\gamma_{22}$ into $\gamma_{11, t}, \gamma_{12, t}, \gamma_{21, t}$ and $\gamma_{22, t}$, for $t=18, \ldots, 28$. To retain a parsimonious model we use flexible cubic spline functions to model the time-varying parameters, see for more discussion Poirier [55]. This approach is justified if we assume that the interactions between employment and crime vary smoothly with age.

Second, to investigate the moderating effect of employment duration we adopt a simple strategy that consists of changing the definition of the employment variable. In the current model specification, the threshold for "serious" employment is 90 days. We vary this definition to study the moderating effect of employment duration. Investigating the influence of employment duration in this manner is convenient since the entire model is adjusted to one change in the construction of the model parameters. When we then compare the parameters for different definitions of employment, we can highlight for which duration of employment there exists interactions with crime.

\section{Results}

In this section, we discuss the parameter estimates from the panel data models that are discussed in the "Methodology" section. We start with the bi-variate model after which we compare the results to more standard uni-variate panel data models and show the extensions for the moderating influences of age and employment duration.

\section{Bi-variate Model Results}

The parameter estimates for the bi-variate dynamic binary choice model are presented in the top panel of Table 1. We estimated the model parameters separately for property and violent offending as well as the overarching category of all offenses. Employment was in each model determined by the 90 day threshold.

First, we discuss the main parameter estimates for the employment (1). We find that the estimates for state dependence are high. The coefficient for $\gamma_{11}$ is always large and significant. This indicates that working at least 90 days at age $t$ is a strong predictor for working at least the same amount of days at age $t+1$. As stated earlier, the coefficient $\gamma_{11}$ measures the structural predictive effect of employment. When inspecting the different crime types, we notice that the value of this employment coefficient barely changes. The predictive cross-effect of property offending on employment, as measured by the parameter $\gamma_{12}$, is significant and negative. No significant effects are found for violent offending and the overarching category of any offending on employment.

Next, we turn to the main parameters in the offending (2). The state dependence in the offending outcomes is sizable for property offenses $\left(\gamma_{22}\right)$. This indicates that prior offending increases future property offending. The same holds when merging all offenses in the any offending category. No significant estimate was found for prior offending on violent offending, the corresponding estimate is also smaller compared to the other crime types. The predictive cross-effect of employment on 
Table 1 Parameter estimation results

\begin{tabular}{|c|c|c|c|c|c|c|}
\hline Parameter & $\begin{array}{c}\text { Work } \\
90 \text { days }\end{array}$ & $\begin{array}{c}\text { Any } \\
\text { offending }\end{array}$ & $\begin{array}{c}\text { Work } \\
90 \text { days }\end{array}$ & $\begin{array}{l}\text { Property } \\
\text { offending }\end{array}$ & $\begin{array}{c}\text { Work } \\
90 \text { days }\end{array}$ & $\begin{array}{c}\text { Violent } \\
\text { offending }\end{array}$ \\
\hline & \multicolumn{6}{|c|}{$\mathrm{Bi}$-variate estimates } \\
\hline$\gamma_{11}$ & $1.474^{*} 0.070$ & & $1.495^{*} 0.070$ & & $1.491^{*} 0.080$ & \\
\hline$\gamma_{12}$ & $-0.176_{0.095}$ & & $-0.253^{*} 0.122$ & & 0.0580 .145 & \\
\hline$\gamma_{21}$ & & $-0.099_{0.091}$ & & $-0.264^{*} 0.124$ & & $0.011_{0.135}$ \\
\hline$\gamma_{22}$ & & $0.294 * 0.089$ & & $0.324^{*} 0.093$ & & 0.1050 .141 \\
\hline$\beta_{1}$ & $0.320_{0.167}$ & $0.016_{0.191}$ & $0.320_{0.165}$ & $-0.099_{0.270}$ & $0.316_{0.173}$ & $-0.152_{0.260}$ \\
\hline$\beta_{2}$ & $-0.070_{0.085}$ & $0.250^{*} 0.091$ & $-0.074_{0.086}$ & 0.1630 .116 & $-0.077_{0.085}$ & $0.284^{*} 0.115$ \\
\hline$\beta_{3}$ & $3.501^{*} 0.367$ & $-2.319^{*} 0.341$ & $4.045^{*} 0.709$ & $-1.324^{*} 0.315$ & $4.036^{*} 0.879$ & $-2.634^{*} 0.619$ \\
\hline$\delta_{0,1}$ & $-4.390^{*} 0.371$ & & $-4.958^{*} 0.697$ & & $-4.970^{*} 0.957$ & \\
\hline$\delta_{0,2}$ & & $1.058^{*} 0.358$ & & $-0.256_{0.348}$ & & 0.8070 .667 \\
\hline$\lambda_{11}$ & $0.430 * 0.093$ & & $0.380^{*} 0.154$ & & $0.434^{*} 0.100$ & \\
\hline$\lambda_{12}$ & $-0.170_{0.096}$ & & $-0.288^{*} 0.146$ & & $-0.310^{*} 0.147$ & \\
\hline$\lambda_{21}$ & & $-0.307^{*} 0.102$ & & $-0.099_{0.122}$ & & $-0.241_{0.135}$ \\
\hline$\lambda_{22}$ & & $0.360^{*} 0.104$ & & $0.380 * 0.154$ & & $0.511^{*} 0.163$ \\
\hline$\sigma_{v, 1}$ & $0.307^{*} 0.068$ & & $0.293^{*} 0.065$ & & $0.302^{*} 0.079$ & \\
\hline$\sigma_{v, 2}$ & & $0.308^{*} 0.070$ & & $0.324^{*} 0.093$ & & $0.299^{*} 0.092$ \\
\hline$\rho_{v}$ & $-0.167^{*} 0.046$ & & $-0.169^{*} 0.053$ & & $-0.119^{*} 0.059$ & \\
\hline \multirow[t]{2}{*}{$\rho_{\epsilon}$} & $-0.119^{*} 0.053$ & & 0.0010 .069 & & $-0.181^{*} 0.073$ & \\
\hline & Uni-variate est & imates & & & & \\
\hline$\gamma_{11}$ & $1.492 * 0.075$ & & $1.507^{*} 0.075$ & & $1.496^{*} 0.081$ & \\
\hline$\gamma_{12}$ & $-0.298^{*} 0.090$ & & $-0.398^{*} 0.128$ & & $-0.024_{0.202}$ & \\
\hline$\gamma_{21}$ & & $-0.264^{*} 0.081$ & & $-0.461^{*} 0.104$ & & $-0.115_{0.275}$ \\
\hline$\gamma_{22}$ & & $0.307^{*} 0.101$ & & $0.463^{*} 0.135$ & & $0.114_{1.203}$ \\
\hline$\beta_{1}$ & $0.331^{*} 0.166$ & $-0.034_{0.193}$ & 0.3230 .172 & $-0.140_{0.293}$ & 0.3210 .318 & $-0.173_{0.487}$ \\
\hline$\beta_{2}$ & $-0.063_{0.086}$ & $0.249^{*} 0.092$ & $-0.072_{0.084}$ & $0.164_{0.129}$ & $-0.075_{0.178}$ & 0.2820 .645 \\
\hline$\beta_{3}$ & $3.977^{*} 0.479$ & $-2.335^{*} 0.834$ & $4.201^{*} 0.634$ & $-1.362^{*} 0.355$ & $4.346^{*} 0.523$ & $-2.631^{*} 0.436$ \\
\hline$\delta_{0,1}$ & $-4.842^{*} 0.482$ & & $-5.097^{*} 0.651$ & & $-5.269^{*} 0.420$ & \\
\hline$\delta_{0,2}$ & & 1.1180 .794 & & $-0.168_{0.405}$ & & 0.8425 .490 \\
\hline$\lambda_{11}$ & $0.405^{*} 0.097$ & & $0.416^{*} 0.099$ & & $0.422^{*} 0.184$ & \\
\hline$\lambda_{12}$ & $-0.132_{0.093}$ & & $-0.064_{0.114}$ & & $-0.166_{0.252}$ & \\
\hline$\lambda_{21}$ & & $-0.224^{*} 0.099$ & & $-0.184_{0.124}$ & & $-0.290 * 0.144$ \\
\hline$\lambda_{22}$ & & $0.316^{*} 0.102$ & & $0.332^{*} 0.135$ & & $0.480_{0.262}$ \\
\hline$\sigma_{v, 1}$ & $0.278^{*} 0.070$ & & $0.272^{*} 0.068$ & & $0.289^{*} 0.066$ & \\
\hline$\sigma_{v, 2}$ & & $0.272^{*} 0.064$ & & $0.276^{*} 0.086$ & & 0.2630 .537 \\
\hline$\rho_{v}$ & 0 & & 0 & & 0 & \\
\hline$\rho_{\epsilon}$ & 0 & & 0 & & 0 & \\
\hline
\end{tabular}

The sample includes $N=493$ individuals and 11 time periods $(t=18, \ldots, 28)$

The standard errors are displayed in lower case and the asterisks indicate significance at the $\alpha=0.05$ level The parameter estimates $\xi_{j, t}$, for $j=1,2$, and $s=18, \ldots, 28$ are not shown 
property offending $\left(\gamma_{21}\right)$ is also significant and negative. For violent offenses and the any offending category, this effect is not significant.

The control variables for the employment equation show that marriage $\left(\beta_{1}\right)$ and exposure $\left(\beta_{3}\right)$ both increase the effect of employment, indicating that life events do influence each other and should be studied in combination, as suggested by Shanahan [63]. For exposure, the estimates are large and significant. The fact that exposure increases the effect of employment is as expected since imprisonment interrupts life-course transitions and therefore will arguably have a negative influence on employment opportunities [5]. Periods without or with little incarceration will therefore positively influence the effect of employment. For parenthood, a small negative estimate is found $\left(\beta_{2}\right)$.

The control variables for the offending equation indicate that overall marriage has a small negative effect on offending. This is in accordance with several empirical studies which found marriage to reduce the offending probability [9]. Exposure has a negative effect on the offending, while parenthood has a positive effect.

The estimates for the parameters of the distributions of the unobserved individualspecific random variables indicate that large fixed differences in the probabilities for offending and employment exists between the individuals in the sample. Both variances of the individual-specific effects are large $\left(\sigma_{v, j}\right)$. Regarding the spurious correlation, we find that for all types of offenses there exists significant negative spurious correlation between the level of crime and the level of employment. The parameter estimate for $\rho_{v}$ is between -0.169 and -0.119 . For violent and any offending, there is also substantial instantaneous spurious correlation $\left(\rho_{\epsilon}\right)$. This indicates that these types of offenses occur more often when the individual is unemployed in the same time period.

Overall, the bi-variate model separates structural effects ( $\gamma$ 's) from spurious correlations ( $\rho$ 's) in a panel data setting. It showed that both structural effects (offending on employment and employment on offending) are negative and significant for property offenses. For violent and any offending, no significant structural effects are found.

\section{Comparison to Standard Panel Data Models}

Next, we compare the parameter estimation results from the bi-variate model to those from standard uni-variate panel data models.

In the bottom panel of Table 1, we present the results from the restricted model that is obtained by fixing the spurious correlation parameters $\rho_{v}$ and $\rho_{\epsilon}$ at zero. We refer to these estimates as the uni-variate estimates, because as we discussed in the "Discussion and Relationship to Uni-variate Models" section under this restriction the models for employment and crime can be estimated separately. We find that incorrectly fixing the spurious correlation parameters to zero leads to overestimating the cross-effects among employment and offending. For example, the effect of employment on any offending is -0.264 and significant according to the uni-variate model whereas the bi-variate model estimates the effect at -0.099 and not significant. The over-estimation is found for all types of offenses and for both directions of the reciprocal relationship. 
Further, one might question whether the correlation between the explanatory variables and the random individual-effects was adequately captured by the specification in Eq. 3. Table 1 shows that several of the $\lambda$ parameters are significant which indicates that such correlation exists. Since, fixed effects models allow for arbitrary correlation between the explanatory variables and the individual-specific effects we have compared our estimates to several fixed effects models. The results (not shown) from these specifications were the same as for the uni-variate random effects models. In particular, they equally over-estimate the predictive effects between employment and crime.

\section{Interactions with Moderating Factors}

Age

Using the panel data model with time-varying structural parameters $\left(\gamma_{11, t}, \gamma_{12, t}, \gamma_{21, t}\right.$ and $\gamma_{22, t}$ instead of $\gamma_{11}, \gamma_{12}, \gamma_{21}$ and $\gamma_{22}$ ), this section focuses on studying the moderating influence of age on the employment-offending association. In particular, the structural parameters are modeled, using flexible cubic spline functions, such that the effects are allowed to vary with age. In Fig. 1, we show all four estimated structural time-varying parameter paths: $\gamma_{11, t}, \gamma_{12, t}, \gamma_{21, t}$ and $\gamma_{22, t}$ for serious (i), property (ii) and violent crimes (iii), and for $t=18, \ldots, 27$.
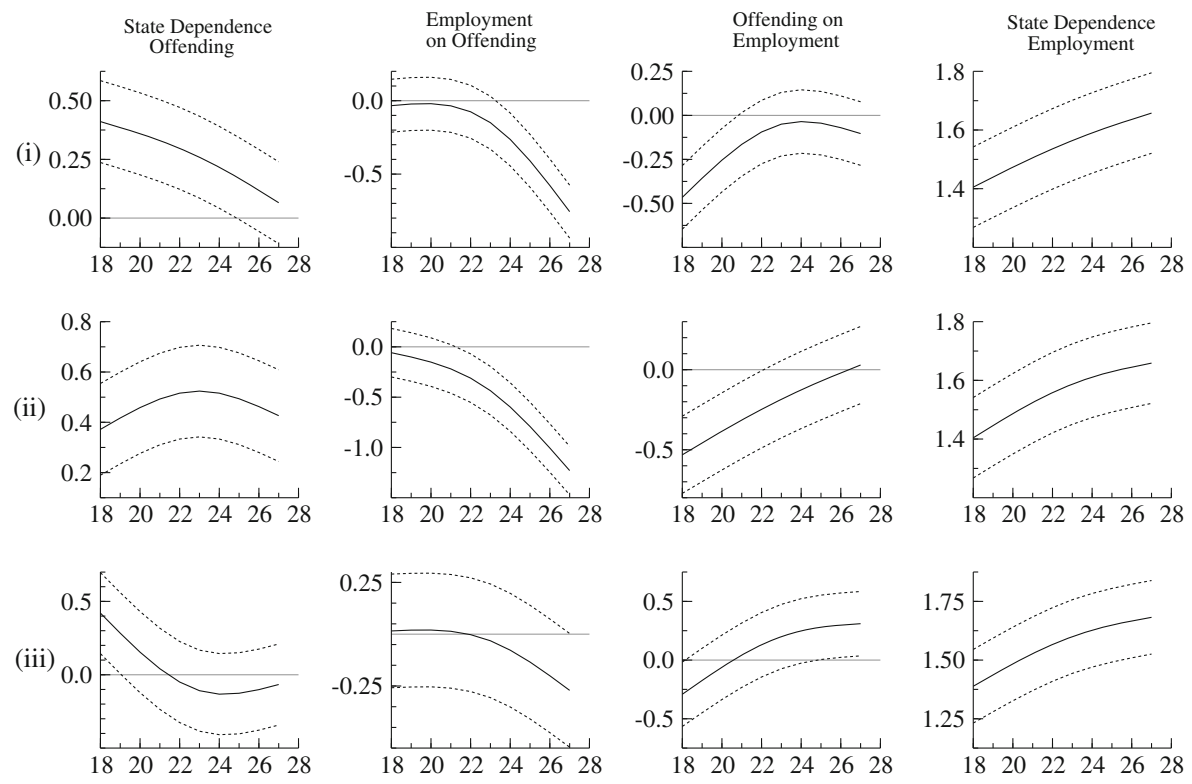

Fig. 1 Age-graded predictive effects among employment and offending. The $x$-axes indicate the age of the individuals. The rows indicate: (i) any offending, (ii) property offenses, and (iii) violent offenses. The dotted lines indicate the point-wise $95 \%$ confidence bounds 
Persistence in offending decreases with maturation for any and violent offending, as the estimates become smaller with age. This decreasing trend illustrates how the sample members age out of crime. For property offending, the effect fluctuates with age, but overall the parameter estimate remains stable and positive.

The cross-effect of previous employment on the three offending types switches from a small positive effect for the younger age cohorts to strong negative estimates for the older ages. Thus, being employed the previous year has a stronger reducing effect on offending for the individuals in the last stages of emerging adulthood than for the younger emerging adults. The effect is most distinct for prior employment on property offending, as the slope of these estimates starts at 0 for age 18 and is about -1.5 for age 27.

For the older age cohorts, the cross-effect of the three offending types on employment becomes smaller. For property offending, little effect on employment is found for the older ages as the estimates are statistically indistinguishable from zero. For violent offending, the estimate switches in sign, from a negative effect in the younger ages to a positive effect on the older age cohorts. The slope of the estimates for previous serious offending on employment becomes less negative with age. However, for the older age cohorts, the sign remains negative. Specifically, the findings for property offending are unexpected since one would assume that the effect of offending on employment would be much less for younger individuals than for adults who are regarded as fully responsible for their own actions.

The estimates show that employment remains strongly dependent on previous employment outcomes for all age cohorts and offending types. The slope of the estimates shows an distinct increase with age.

\section{Employment Duration}

Following the theoretical literature, it is expected that the more days an individual is employed the more persistent the employment process becomes, hereby causing a decrease in offending. In order to study the effect of employment duration, we vary the definition of the employment variable according to different durations of employment per year. Several analysis were conducted, where individuals are considered as employed when employment totals 10 days a year, 30 days a year, 50 days, and so forth until 350 days per year.

Figure 2 shows the structural parameter estimates from this analysis for any (i), property (ii), and violent crimes (iii). We find that the state dependence for offending remains stable during the different employment durations for any, property and violent offending. Indicating that employment duration does not contribute to the previously found effect of prior offending on future offending.

The predictive cross-effect of employment on offending shows a steep decrease in the estimates for approximately the first 100 days of employment. After this period, the slope of the effect flattens out. This holds for all three types of offenses. For violent offending, very short employment durations are even associated with a small positive effect. For property offending, we find a negative estimate for all employment durations. However, for all the offending types, the estimates are often not significant. 
(i)

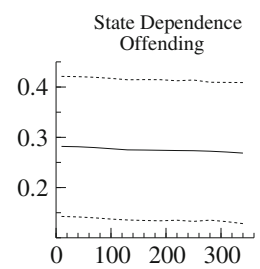

(ii)

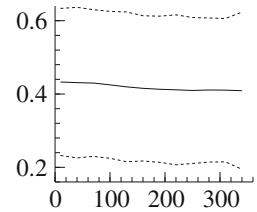

(iii)

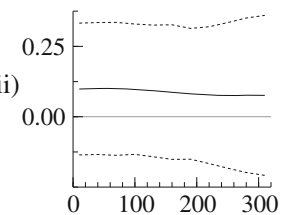

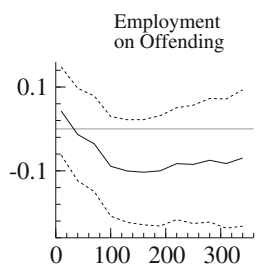
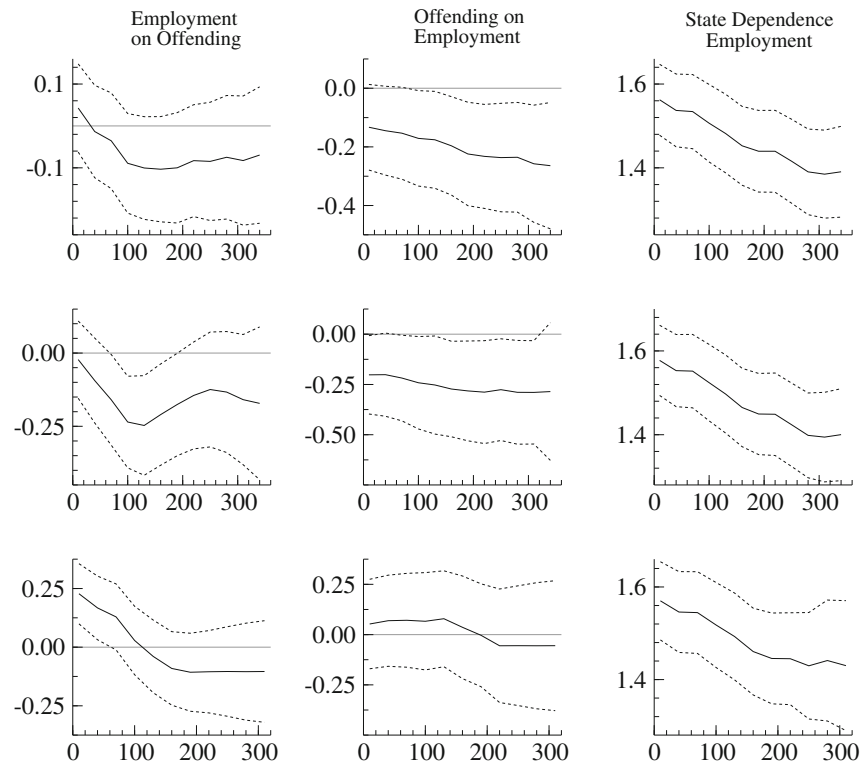

Fig. 2 Predictive effects for different values of the employment threshold (solid line). The $x$-axes indicate the number of working days used to define the working indicator. The rows indicate: (i) any offending, (ii) property offenses, and (iii) violent offenses. The dotted lines indicate the point-wise $95 \%$ confidence bounds

The cross-effects of offending on employment show that the effect of property offending increases with employment duration, as the estimates become more negative. This indicates that previous property offending will reduce the probability for long-term employment duration. The same holds for the category of any offending. Violent offending has limited effect on employment duration, as the estimate is marginally positive for short employment duration and becomes slightly negative with the increase of employment duration.

Finally, regarding the state dependence of employment, it is found that the effect of previous employment on future employment is positive, yet is decreases when employment is of longer duration and therefore possibly more stable.

\section{Conclusion and Discussion}

In this study, we used a large sample of juvenile sex offenders to study the $b i$ directional relationship between employment and crime and the influence of the moderating factors age and employment duration on this relationship. The sample was followed in early adulthood (age 18-28). Our main empirical results showed, in correspondence with the theoretical literature for general offenders, that employment was a negative predictor for offending. So even for this special sample of juvenile sex offenders, a group that is limited in employment possibilities due to criminal justice policies, prior employment was found to have a reducing effect on future 
offending, implicating the salience of employment. However, the findings also highlight a possible side-effect of the employment policies for individuals convicted for a sexual offense, as offending will likely increase if the sample members experience difficulties finding employment.

Similarly, offending was found to be a negative predictor for employment. These estimates were both significant for property offending only. For any offending and its sub-class of violent offenses we found no significant effects. While the 1-year ahead predictive effect of violent offending on employment is not significant, the contemporaneous spurious correlation is large and negative. This indicates that a higher offending probability is strongly associated with a lower employment probability in the same year. But this is caused by common unobserved processes and not directly by committing a violent offense in the previous year. It does not rule out the possibility that there is a contemporaneous causal effect from violent offending on employment but we do rule out that there is a predictive channel. For property offending, we find exactly the opposite, the spurious correlation is close to zero but there are strong structural predictive effects among employment and property offending. This corresponds to the findings for general high-risk samples in Van der Geest et al. [78] and Mesters et al. [42] who also find larger effects for property offending.

The finding that the association between employment and offending is only established for property crimes corresponds with the economic theories, such as the rational choice theory. We found that prior offending increases future property offending and that prior employment decreases future property offending. A likely conclusion is that the financial gains of property crimes or legal employment motivate the juvenile sex offenders to make a trade-off between employment or crime. Hence, the financial aspects seem pivotal in influencing the rational decision between legal employment or property offending for the current sample.

We also found employment to be persistent: when the sample member is employed in a particular year the probability for employment in the next year increases. The same was found for offending: current offending increases the probability for future offending. Combined, this shows that a somewhat "vicious" circle exists where offending increasing future offending and decreasing the probability for employment. This conforms to the process of cumulative disadvantage hypothesized by Sampson and Laub [57]. However, as the employment-offending association is reciprocal (for property offending) with strong state dependence, the workings of "hooks for change" as postulated by Sampson and Laub [57] also fit our findings. Once the sample member manages to gain employment this will reduce the gain from offending, and the likelihood that employment is continued will increase. This again highlights the salience of employment for the current sample of individuals with a history of sexual offending.

The routine activities theory is also apparent in these results. If the sample member is engaged in regular employment, time to commit crimes is limited. Therefore, employment will inhibit offending behavior and at the same time increasing the probability of continued employment. Next, we studied the age-graded effects of employment on offending. Several theoretical age-graded frameworks state that the younger age cohorts (age 18 up to about 20) will experience little benefit in terms of reduced offending from being employed. However, with maturation the 
effect of employment on offending will become stronger, leading to a reducing effect from employment on offending for the older age cohorts, i.e., those in the last stages of early adulthood. The analysis in this study confirmed this theoretical framework. Therefore, our findings—-somewhat counter-intuitively_advise against policies aimed at guidance towards employment for criminally active young people, as a limited effect was found. Our analysis even showed that within the sample of juvenile sex offenders the effect of employment on all three offending types switches in sign, from a very small positive effect at young ages to a large negative effect for the older age cohorts. Indicating that policies aimed at guidance towards employment may be important for the individuals in the older age cohorts.

The other structural effects showed that the effect of serious and property offending on employment over time becomes less important and even non-existent at the older ages, indicating that these offenses affect employment for the younger ages more than in the later stages of emerging adulthood. A possible explanation for this finding could be that those individuals in the later stages of emerging adulthood follow a criminal career and are not employed, or self select into jobs where offending is less damaging.

Further, we found that offending has an increasing effect on offending; however, this effect becomes smaller with the coming of age. This could point to the intuitive aging-out of crime effect, where the effect of prior offending over time becomes smaller for future offending. Individuals could therefore be less inclined to offend when they are at the end of the emerging adulthood period. The aging-out of crime effect is also assumed in life-course theories, where the gain of adolescence or early adulthood offending is assumed to be increased as compared to the gain of offending in adulthood. In adulthood, offending will limit chances of adult roles, therefore limiting the gain of offending during this age period Sampson and Laub [57]. The aging-out of crime effect was mainly found for serious and violent offending. For property offending the estimates seemed more stable over the age years. For employment the opposite is detected, over time the effect of employment becomes more positive. This could denote to a certain aging-in employment effect where holding a job at the older ages has a larger increasing effect of future employment than in the early ages of adulthood. Again, this could indicate the salience of employment for the older age cohorts of juvenile sex offenders as an instrument for desistance or the simple aging-out of crime.

In the empirical study, we also looked at variation in employment duration to investigate the importance of stable employment. Following theoretical and empirical literature, one would expect that the more days an individual is employed, the more persistent the employment process becomes, causing a decrease in the gain of offending. The analysis confirmed this hypothesis; however, the effect fluctuates and is often not significant. This lead us to conclude that the influence of employment duration on the cross-effect between employment and offending is weak. However, it does show that for this sample offending becomes increasingly detrimental to full societal integration (in terms of holding long-term jobs) at higher ages. The effect of previous employment on future employment decreased with employment duration, indicating that short term employment had a more positive effect on future employment than employment on long-term employment duration. 
For the state dependence estimates of offending, we found them to be almost identical for the different measures of employment duration and age cohorts. In conclusion, we found that not only the association is reciprocal for property offending, but it is also influenced by moderating factors such as age and to a lesser extend employment duration and the interaction between them. In particular, effects may shift over the life-course, possibly due to a change in mindset or a change in relevant institutions of social control with the coming of age as indicated by Arnett [6] and Sampson and Laub [57]. As shown previously, all findings in this study resemble previous empirical accounts on the employment-crime association for general offenders, this leads us to believe that the long-term impact of sexual offending is not different from other types of offending. This yields important implications for policy and general 'treatment' of juvenile sex offenders. Since we found that employment does not influence general offending or violent offending, a careful assumption could be that the employment restrictions for juvenile sex offenders do not influence any offending, like sexual offending, as they are intended to do. However, further research is needed to confirm the effectiveness of the employment exclusion policy, as we are unable to study types of employment.

This study has strong points. First of all, we used a prospectively gathered, rich dataset consisting of long-term objective and detailed information on offending and employment. Moreover, we employed advanced methods to control and allow for reciprocal effects, state dependence and unobserved heterogeneity. On the other hand, our study has limitations. Our employment variable might be thought of as incomplete, since we were only able to look at official employment registration, and we have no measures of "unofficial" labor. Also, there is no knowledge of whether the individuals were employed full-time or part-time. However, it is likely that most contracts would have been (almost) full-time given that the employment records showed that very few applied for supplementary benefits that citizens in the Netherlands are entitled to if their income is below a certain minimum. Our offending variable is also based on official data, which could lead to an understimation of the actual number of offending. The follow-up period constitutes the start of adulthood age 18 up to 28 , with current changes in society we might not be able to capture the entire effect of the employment-crime association as a individuals in their late twenties might still explore the various life possibilities. For example, Krahn et al. [29] found that employment success was not established until the age of 32. With an upper age limit of 28 , the found effect could therefore still change with maturation. Also, we do not know whether people were cohabiting or otherwise romantically involved: we only know from the register data if people have officially registered as partners whether by marriage or through a registered partnership. We also do not have data on disabilities, or drugs addiction, or mental health issues. All in all, through the register data we could only study the "outside appearance" of these individuals' lives. More in-depth research with for instance interviews is needed, to be able to further disentangle the employment-offending association. Yet, the next step will be to use the registered data to look at individual characteristics (beyond age) to determine whether the effect of employment is moderated by stable individual characteristics such as intelligence, personality characteristics, or educational level. 
Open Access This article is distributed under the terms of the Creative Commons Attribution 4.0 International License (http://creativecommons.org/licenses/by/4.0/), which permits unrestricted use, distribution, and reproduction in any medium, provided you give appropriate credit to the original author(s) and the source, provide a link to the Creative Commons license, and indicate if changes were made.

\section{References}

1. Alessie, R., Hochguertel, S., \& van Soest, A. (2004). Ownership of stocks and mutual funds: a panel data analysis. The Review of Economics and Statistics, 86, 783-796.

2. Apel, R., Bushway, S.D., Brame, R., Haviland, A.M., Nagin, D.S., \& Paternoster, R. (2007). Unpacking the relationship between adolescent employment and antisocial behavior: a matched samples comparison. Criminology, 45, 67-97.

3. Apel, R., Bushway, S.D., Paternoster, R., Brame, R., \& Sweeten, G. (2008). Using state child labor laws to identify the causal effect of youth employment on deviant behavior and academic achievement. Journal of Quantitative Criminology, 24, 337-362.

4. Apel, R., Paternoster, R., Bushway, S.D., \& Brame, R. (2006). A job isn't just a job: the differential impact of formal versus informal work on adolescent problem behavior. Crime and Delinquency, 52, 333-369.

5. Apel, R., \& Sweeten, G. (2010). The impact of incarceration on employment during the transition to adulthood. Social Problems, 57, 448-479.

6. Arnett, J.J. (2004). Emerging adulthood; the winding road from the late teens through the twenties. Oxford: Oxford University Press.

7. Becker, G.S. (1968). Crime and punishment: an economic analysis. Journal of Political Economy, 78, 169-217.

8. Becker, H.S. (1963). Outsiders: studies in the sociology of deviance. New York: Macmillan.

9. Bersani, B.E., Laub, J.H., \& Nieuwbeerta, P. (2009). Marriage and desistance from crime in the Netherlands: do gender and socio-historical context matter? Journal of Quantitative Criminology, 25, 3-24.

10. Bushway, S., \& Reuter, P. (2002). Labor markets and crime risk factors. In Sherman, L.W., Farrington, D.P., Welsh, B.C., \& MacKenzie, D.L. (Eds.) Preventing crime. Routledge: Abingdon.

11. Butler, S.M., \& Seto, M.C. (2002). Distinguishing two types of juvenile sex offenders. Journal of the American Academy of Child and Adolescent Psychiatry, 41, 83-90.

12. Cale, J., Smallbone, S., Rayment-McHugh, S., \& Dowling, C. (2016). Offense trajectories, the unfolding of sexual and non-sexual criminal activity, and sex offense characteristics of adolescent sex offenders. Sexual Abuse: Journal of Research and Treatment, 28, 791-812.

13. Chamberlain, G. (1980). Analysis of covariance with qualitative data. The Review of Economic Studies, 47, 225-238.

14. Cohen, L.E., \& Felson, M. (1979). Social change and crime rate trends: a routine activity approach. American Sociological Review, 44, 588-608.

15. Crutchfield, R.D., \& Pitchford, S.R. (1997). Work and crime: the effects of labor stratification. Social Forces, 76, 93-118.

16. Ehrlich, I. (1973). Participation in illegal activities: a theoretical and empirical investigation. Journal of Political Economy, 81, 521-565.

17. Evans, D.N., \& Cubellis, M.A. (2015). Coping with stigma: how registered sex offenders manage their public identities. American Journal of Criminal Justice, 40, 593-619.

18. Freeman, R.B. (1999). The economics of crime. In Ashenfelter, O., \& Card, D.E. (Eds.) Handbook of labor economics (Vol. 3C, pp. 3529-3571). Amsterdam: Elsevier Science.

19. Giordano, P.C., Cernkovich, S.A., \& Rudolph, J.L. (2002). Gender, crime and desistance: toward a theory of cognitive transformation. American Journal of Sociology, 107, 990-1064.

20. Hanson, R.K., \& Harris, A.J.R. (1998). Dynamic predictors of sexual recidivism. Ottawa: Solicitor General of Canada.

21. Hargreaves, C., \& Francis, B. (2014). The long term recidivism risk of young sexual offenders in England and Wales - enduring risk or redemption? Journal of Criminal Justics, 42, 164-172.

22. Hirschi, T. (1969). Causes of delinquency. Berkeley: University of California Press.

23. Holzer, H.J., Raphael, S., \& Stoll, M.A. (2004). Will employers hire ex-offenders? employer perceptions, background checks and their determinants. In Patillo-McCoy, M., Weiman, D., \& Western, B. (Eds.) Imprisoning America: the social effects of mass incarceration. New York: Sage. 
24. Horney, J., Osgood, D.W., \& Haen Marshall, I. (1995). Criminal careers in the short-term: intraindividual variability in crime and is relation to local life circumstances. American Sociological Review, 60, 655-673.

25. Hyslop, D.R. (1999). State dependence, serial correlation and heterogeneity in intertemporal labor force participation of married women. Econometrica, 67, 1255-1294.

26. Keane, M.P. (2013). Panel data discrete choice models of consumer demand. In Baltagi, B.D. (Ed.) The Oxford handbook of panel data. Oxford: Oxford University Press.

27. Keane, M.P., \& Sauer, R.M. (2009). Classification error in dynamic discrete choice models: implications for female labor supply behavior. Econometrica, 77, 975-991.

28. Kling, J.R. (2006). Incarceration length, employment and earnings. American Economic Review, 96, $863-876$.

29. Krahn, H.J., Howard, A.L., \& Galambos, N.L. (2015). Exploring or Floudering? The meaning of employment and educational fluctuations in emerging adulthood. Youth \& Society, 47, 245-266.

30. Kruttschnitt, C., Uggen, C., \& Shelton, K. (2000). Predictors of desistance among sex offenders: the interaction of formal and informal social controls. Justice Quarterly, 17, 61-87.

31. Lageson, S., \& Uggen, C. (2013). How work affects crime-and crime affects work-over the life course. In Gibson, C.L., \& Krohn, M.D. (Eds.) Handbook of life-course criminology: emerging trends and directions for future research. New York: Springer.

32. Laws, D.R., \& Ward, T. (2011). Desistance from sex offending: alternatives to throwing away the keys. New York: Guilford Press.

33. Lemert, E.M. (1967). Human deviance, social problems and social control. Englewood Cliffs: Prentice-Hall.

34. Link, B.G. (1987). Understanding labeling effects in the area of mental disorders: an assessment of the effects of expectations of rejection. American Sociological Review, 52, 96-112.

35. Loeffler, C.E. (2013). Does imprisonment alter the life course? Evidence on crime and employment from a natural experiment. Criminology, 51, 137-166.

36. Lussier, P., Berg van den, C.J.W., Bijleveld, C.C.J.H., \& Hendriks, J. (2012). A developmental taxonomy of juvenile sex offenders for theory, research, and prevention: the adolescent-limited and the high-rate slow desister. Criminal Justice and Behavior, 39, 1559-1581.

37. Lussier, P., \& Blokland, A. (2014). The adolescence-adulthood transition and robin's continuity paradox: criminal career patterns of juvenile and adult sex offenders in a prospective longitudinal birth cohort study. Journal of Criminal Justice, 42, 153-163.

38. MacKenzie, D.L., \& De Li, S. (2002). The impact of formal and informal social controls on the criminal activities of probationers. Journal of Research in Crime and Delinquency, 39, 243-276.

39. Merton, R.K. (1938). Social structure and anomie. American Sociological Review, 3, 672-682.

40. Merton, R.K. (1968). Social theory and social structure. New York: The Free Press.

41. Mesters, G., \& Koopman, S.J. (2014). Generalized dynamic panel data models with random effects for cross-section and time. Journal of Econometrics, 180, 127-140.

42. Mesters, G., Van der Geest, V., \& Bijleveld, C.C.J.H. (2016). Crime, employment and social welfare: an individual-level study on disadvantaged males. Journal of Quantitative Criminology, 32, 159-190.

43. Moffitt, T.E. (1993). Adolescence-limited and life-course-persistent antisocial behavior: a developmental taxonomy. Psychological Review, 100, 674-701.

44. Mundlak, Y. (1978). On the pooling of time series and cross section data. Econometrica, 46, 69-85.

45. Mustard, D.B. (2010). How do labor markets affect crime? New evidence on an old puzzle. In Benson, B.L., \& Zimmerman, P.R. (Eds.) Handbook on the economics of crime. New York: Edward Elgar Publishing.

46. Nagin, D.S., Cullen, F.T., \& Jonson, C.L. (2009). Imprisonment and reoffending. In Tonry, M. (Ed.) Crime and justice: a review of research (Vol. 38, pp. 115-200). Chicago: University of Chicago Press.

47. Nagin, D.S., \& Paternoster, R. (1991). On the relationship of past to future participation in delinquency. Criminology, 29, 163-189.

48. Nagin, D.S., \& Paternoster, R. (2000). Population heterogeneity and state dependence: future research. Journal of Quantitative Criminology, 16, 117-145.

49. Nagin, D.S., \& Waldfogel, J. (1995). The effects of criminality and conviction on the labour market status of young british offenders. International Review of Law and Economics, 15, 109-126.

50. Pager, D. (2003). The mark of a criminal record. American Journal of Sociology, 108, 937-975.

51. Pager, D. (2007). Marked: race, crime and findings work in an era of mass incarceration. Chicago: University of Chicago Press. 
52. Pager, D., Western, B., \& Bonikowski, B. (2009). Discrimination in a low-wage market: a field experiment. American Sociological Review, 74, 777-799.

53. Paternoster, R., Bushway, S.D., Brame, R., \& Apel, R. (2003). The effect of teenage employment on delinquency and problem behaviors. Social Forces, 82, 297-335.

54. Piquero, A.R., MacDonald, J.M., \& Parker, K.F. (2002). Race, local life circumstances, and criminal activity. Social Science Quarterly, 83, 654-670.

55. Poirier, D.J. (1976). The econometrics of structural change: with special emphasis on spline functions. North-Holland.

56. Raphael, S. (2011). Improving employment prospects for former prison inmates: challenges and policy. In Cook, P.J., Ludwig, J., \& McCrary, J. (Eds.) Controlling crime: strategies and tradeoffs. Chicago: University of Chicago Press.

57. Sampson, R.J., \& Laub, J.H. (1993). Crime in the making: pathways and turning points through life. Cambridge: Harvard University Press.

58. Sampson, R.J., \& Laub, J.H. (1997). A life-course theory of cumulative disadvantage and the stability of delinquency. In Thornberry, T.P. (Ed.) In developmental theories of crime and delinquency (pp. 133-161). Piscataway: Transaction Publishers.

59. Sampson, R.J., \& Laub, J.H. (2003). Life-course-desisters? Trajectories of crime among delinquent boys followed to age 70. Criminology, 41, 555-592.

60. Sampson, R.J., \& Laub, J.H. (2005). A life-course view of the development of crime. ANNALS of the American Academy of Political and Social Science, 602, 12-45.

61. Savolainen, J. (2009). Work, family and criminal desistance: adult social bonds in a nordic welfare state. British Journal of Criminology, 49, 285-304.

62. Seto, M.C., \& Lalumière, M.L. (2010). What is so special about male adolescent sexual offending? A review and test of explanations through meta-analysis. Psychological Bulletin 136.

63. Shanahan, M.J. (2000). Pathways to adulthood in changing societies: variability and mechanisms in life course perspective. Annual Review of Sociology, 26, 667-692.

64. Shover, N. (1996). Great pretenders: pursuits and careers of persistent thieves. Boulder: Westview.

65. Skardhamar, T., \& Savolainen, J. (2014). Changes in criminal offending around the time of job entry: a study of employment and desistance. Criminology, 52, 263-291.

66. Smallbone, S.W. (2006). Social and psychological factors in the development of delinquency and sexual deviance. New York: Guilford Press.

67. Staff, J., \& Uggen, C. (2003). The fruits of good work: work experiences and adolescent deviance. Journal of Research in Crime and Delinquency, 40, 263-290.

68. Stolzenberg, L.J., \& D' Alessio, S.J. (2007). The effect of divorce on domestic crime. Crime \& Delinquency, 53, 281-302.

69. Sutherland, E.H., \& Cressey, D.R. (1978). Principles of criminology, J.B. Lippincott, Philadelphia.

70. Tewksbury, R. (2005). Collateral consequences of sex offender registration. Journal of Contemporary Criminal Justice, 21, 67-81.

71. Thornberry, T.P., \& Christenson, R.L. (1984). Unemployment and criminalinvolvement: an investigation of reciprocal causal structures. American Sociological Review, 49, 398-411.

72. Uggen, C. (1999). Work as turning point in the life course of criminals: a duration model of age, employment, and recidivism. American Sociological Review, 67, 529-546.

73. Uggen, C. (2000). Ex-offenders and the conformist alternative: a job quality model of work and crime. Social Problems, 46, 127-151.

74. Uggen, C., \& Wakefield, S. (2008). What have we learned from longitudinal studies of work and crime? In Liberman, A.M. (Ed.) The long view of crime: a synthesis of longitudinal research (pp. 198240). New York: Springer.

75. Van den Berg, C.J.W., Bijleveld, C.C.J.H., \& Hendriks, J. (2011). Jeugdige zedendelinquenten. lange termijn criminele carrieres en achtergrondkenmerken. Tijdschrift voor Criminologie, 53, 227243.

76. Van den Berg, C.J.W., Bijleveld, C.C.J.H., \& Hendriks, J. (2015). The juvenile sex offender: criminal careers and life events. Sexual Abuse: Journal for Research and Treatment. In press.

77. Van den Berg, C.J.W., Bijleveld, C.C.J.H., Hendriks, J., \& Mooi-Reci, I. (2014). The juvenile sex offender: the effect of employment on offending. Journal of Criminal Justice, 42, 145-152.

78. Van der Geest, V., Blokland, A., \& Bijleveld, C.C.J.H. (2011). The effects of employment on longitudinal trajectories of offending: a follow up in high risk youths from ages 18 - 32. Criminology, 49, 1195-1234. 
79. Van Wijk, A.V., Van Horn, J., Bullens, R., Bijleveld, C.C.J.H., \& Doreleijers, T. (2005). Juvenile sex offenders: a group on its own? International Journal of Offender Therapy an Comparative Criminology, 49, 25-36.

80. Verbruggen, J., Blokland, A., \& van der Geest, V. (2012). Effects of employment and unemployment on serious offending in a high-risk sample of men and women from ages 18 to 32. British Journal of Criminology, 52, 845-869.

81. Visher, C.A., Winterfield, L., \& Coggeshall, M.B. (2005). Ex-offender employment programs and recidivism: a meta-analysis. Journal of Experimental Criminology, 1, 295-315.

82. Wadsworth, T. (2006). The meaning of work: conceptualizing the deterrent effect of employment on crime among young adults. Sociological Perspectives, 49, 343-368.

83. Ward, T., \& Beech, A.R. (2008). An integrated theory of sexual offending. In Laws, D.R., \& O’Donohue, W.T. (Eds.) Sexual deviance (pp. 133-161). New York: The Guilford Press.

84. Western, B. (2006). Punishment and inequality in America. New York: Russel Sage Foundation.

85. Wooldridge, J.M. (2005). Simple solutions to the initial conditions problem in dynamic, nonlinear panel data models with unobserved heterogeneity. Journal of Applied Econometrics, 20, 39-54.

86. Wright, J.P., \& Cullen, F.T. (2000). Juvenile occupational delinquency. Criminology, 38, 863-896.

87. Wright, J.P., Cullen, F.T., \& Williams, N. (2002). The embeddedness of adolescent employment and participation in delinquency: a life course perspective. Western Criminology Review, 4, 1-19. 